\title{
A Survey of Satisfaction with Treatment among Brain Tumor Patients
}

\author{
Gunjesh Kumar Singh ${ }^{1}$ Mitali Alone ${ }^{1} \quad$ Nandini Menon ${ }^{1}$ \\ Ochin Dale ${ }^{1}$ Arti Bhelekar ${ }^{1} \quad$ Vijay M. Patil ${ }^{1}$ \\ ${ }^{1}$ Department of Medical Oncology, Tata Memorial Centre, Homi \\ Bhabha National Institute (HBNI), Mumbai, Maharashtra, India
}

\section{South Asian J Cancer:2021;9:262}

Satisfaction among the patients is an important parameter to assess the quality of health care services. ${ }^{1}$ Satisfaction in health care depends on various aspects like satisfaction with clinicians, pharmacists, and nursing staffs, which includes health care staff's communication skills, technical competence, and patient's confidence along with trust on them. Patient's expectations have also an important role in satisfaction. ${ }^{2}$ Patients with brain tumors are comparatively more physically disabled and have a shorter life span. Hence, the knowledge of the satisfaction rate with regard to the quality of currently provided health care services is indispensable in this specific population.

Brain tumor patients who visited our Neuro MedicalOncology Outpatient Department were invited and those who were willing to participate in the study were given the questionnaire to collect the satisfaction data using functional assessment of chronic illness therapy treatment satisfaction-general (FACIT-TS-G) and FACIT-TS-patient satisfaction (PS) scale (version 4). ${ }^{3}$ Multiple regression analysis was performed to identify the factors affecting patient satisfaction. There were a total of 40 patients and the median age was 36.5 (13-64) years. In FACIT-TS-G scoring, 23/40 (57.5\%) patients rated the overall treatment as excellent (score: $4 / 4)$, while $10 / 40$ (25\%) and $7 / 40$ (17.5\%) rated it as very good (score: $3 / 4$ ) and good (score: 2/4), respectively. While the FACIT

DOI https://doi.org/10.1055/s-0041-1729494 ISSN 2278-330X

How to cite this article: Singh G. K, Alone M, Menon N, Dale O, Bhelekar A, Patil V.M. A Survey of Satisfaction with Treatment among Brain Tumor Patients South Asian J Cancer 2021;9(4):262.
Address for correspondence Vijay M. Patil, MBBS, MD, DM, Department of Medical Oncology, Tata Memorial Hospital, Parel, Mumbai, Maharashtra 400012, India (e-mail: vijaypgi@gmail.com).

TS-PS survey showed the care was excellent (score: 4/4) according to $26 / 40$ (65\%) patients, it was very good, good, and fair according to $8 / 40$ (20\%), 3/40 (7.5\%), and 3/40 (7.5\%), respectively. There was no association between satisfaction and factors such as age, sex, Eastern Cooperative Oncology Group Performance Status (ECOG PS), category, and monthly income.

The patients in our study were satisfied with the care and treatment they received. Also, the satisfaction score was not influenced by any of the factors.

\section{Conflict of Interest}

None.

\section{References}

1 Andrzejewski N, Lagua RT. Use of a customer satisfaction survey by health care regulators: a tool for total quality management. Public Health Rep 1997;112(3):206-210, discussion 211

2 Urden LD. Patient satisfaction measurement: current issues and implications. Outcomes Manag 2002;6(3):125-131

3 Peipert JD, Beaumont JL, Bode R, Cella D, Garcia SF, Hahn EA. Development and validation of the functional assessment of chronic illness therapy treatment satisfaction (FACIT TS) measures. Qual Life Res 2014;23(3):815-824 (c) 2021. MedIntel Services Pvt Ltd.

This is an open access article published by Thieme under the terms of the Creative Commons Attribution-NonDerivative-NonCommercial-License, permitting copying and reproduction so long as the original work is given appropriate credit. Contents may not be used for commercial purposes, or adapted, remixed, transformed or built upon. (https://creativecommons.org/licenses/by-nc-nd/4.0/).

Thieme Medical and Scientific Publishers Private Ltd A-12, Second Floor, Sector -2, NOIDA -201301, India 